\title{
Inhibitory effects of Persicariae Rhizoma aqueous extracts on experimental periodontitis and alveolar bone loss in Sprague-Dawley rats
}

\author{
SU JIN KANG ${ }^{1,2}$, EUN KYUNG LEE ${ }^{1,2}$, CHANG HYUN HAN ${ }^{3}$, BONG HYO LEE ${ }^{1,4}$, \\ YOUNG JOON LEE ${ }^{1,2}$ and SAE KWANG KU ${ }^{1,5}$
}

${ }^{1}$ The Medical Research Center for Globalization of Herbal Formulation and

${ }^{2}$ Department of Preventive Medicine, College of Korean Medicine, Daegu Haany University, Gyeongsan, Gyeongbuk 38610;

${ }^{3}$ Department of Medical History and Literature, Korean Institute of Oriental Medicine, Daejeon 34054;

Departments of ${ }^{4}$ Acupuncture, Moxibustion and Acupoint and ${ }^{5}$ Anatomy and Histology, College of

Korean Medicine, Daegu Haany University, Gyeongsan, Gyeongbuk 38610, Republic of Korea

Received May 7, 2015; Accepted June 14, 2016

DOI: $10.3892 /$ etm.2016.3499

\begin{abstract}
Persicariae Rhizoma (PR) is the dried stem parts of Persicaria tinctoria $\mathrm{H}$. Gross (Polygonaceae), and has been traditionally used as anti-inflammatory and detoxifying agent. In the present study, the effects of PR aqueous extracts on ligation-induced experimental periodontitis (EPD) and associated alveolar bone loss in rats were examined. Following the induction of EPD in rats, PR extracts were orally administered once a day for 10 days, and the changes and gains in body weight, alveolar bone loss and total aerobic bacterial counts of buccal gingiva were observed with histopathological analysis. In addition, anti-inflammatory effects were evaluated by monitoring myeloperoxidase (MPO) activities, and interleukin (IL)-1 $\beta$ and tumor necrosis factor (TNF)- $\alpha$ contents, and anti-oxidant effects were investigated by measuring inducible nitric oxide synthase (iNOS) activities and malondialdehyde (MDA) levels. Bacterial proliferation, periodontitis and associated alveolar bone loss induced by ligature placement were significantly and dose-dependently inhibited by the treatment with PR extracts. The inhibitory effects of $200 \mathrm{mg} / \mathrm{kg}$ PR were similar to those of $5 \mathrm{mg} / \mathrm{kg}$ indomethacin on ligation-induced periodontitis and associated alveolar bone losses in this study.
\end{abstract}

Correspondence to: Professor Young Joon Lee, Department of Preventive Medicine, College of Korean Medicine, Daegu Haany University, 1 Haanydae-ro, Gyeongsan, Gyeongbuk 38610, Republic of Korea

E-mail: gksxntk@dhu.ac.kr

Professor Sae Kwang Ku, Department of Anatomy and Histology, College of Korean Medicine, Daegu Haany University, 1 Haanydae-ro, Gyeongsan, Gyeongbuk 38610, Republic of Korea E-mail: gucci200@hanmail.net

Key words: periodontitis, Persicariae Rhizoma, Persicaria tinctoria H. Gross, alveolar bone loss, rat
The results suggest that PR effectively inhibits ligature placement-induced periodontitis and alveolar bone loss in rats via antibacterial, antioxidative and anti-inflammatory activities.

\section{Introduction}

Periodontitis is a chronic inflammatory disease in which destruction of the tooth-supporting connective tissue and cementum, leukocyte infiltration, bone resorption and the formation of periodontal pockets occur (1). The pathogenesis of periodontitis involves the presence of bacterial plaque, which initiates a local inflammatory reaction (2). The inflammatory response can comprise edema, the infiltration of leukocytes and the release of inflammatory mediators, with subsequent periodontal pocket formation, detachment of connective tissue and alveolar bone resorption, ultimately leading to tooth loss $(3,4)$. Periodontitis is most frequently caused by bacteria, with the toxins, enzymes and metabolites associated with the bacteria in dental plaque playing an important role in the initiation of the inflammatory process (5). Recently, the involvement of nitric oxide activities and oxidative stresses in the pathogenesis of periodontitis has been revealed (6), and numerous antioxidants have shown favorable effects on periodontitis and associated alveolar bone loss (7-9).

Natural products are of increasing interest to pharmaceutical industry and potential sources of new bioactive molecules (10). Herbs, medicinal plants and their extracts contain antioxidants that may be useful in the treatment of various diseases (11). Persicariae Rhizoma (PR) is dried stem parts of Persicaria tinctoria H. Gross (Polygonaceae), and has been traditionally used as anti-inflammatory and detoxifying agent in Korea (12). PR contains two biologically active anti-inflammatory and antioxidative dyes, namely purple indirubin and blue indigo (13). Indirubin, a 3,2'-bisindole isomer of indigo, was initially identified as the active ingredient of a traditional Chinese medicine preparation, Danggui Longhui Wan, which is used to treat various chronic diseases (14). Indirubin derivatives exhibit strong anti-inflammatory and 
anti-leukemic activities (15). It has previously been shown that indirubin is a potent inhibitor of wide range of kinases, but, in particular, it strongly suppresses the activation of cyclin-dependent kinases (16). Herbal extracts containing indigo or its derivatives also have been shown to have potent antibacterial (17), antitumor (18), anti-inflammatory (19) and antioxidant (20) activities. Accordingly, PR is a promising candidate for the treatment of periodontal diseases.

However, there have been no studies examining the effects of PR on experimental periodontitis (EPD) or related alveolar bone loss. Thus, the present comparative study of PR aqueous extracts and indomethacin on ligature-induced EPD and alveolar bone loss in rats was conducted.

\section{Materials and methods}

Animals. In total, 48 healthy male Sprague-Dawley (Slc:SD) rats (Japan SLC, Inc., Shizuoka, Japan), aged 6 weeks and weighing 170-190 g, were used after acclimatization for 10 days. The rats were housed four per polycarbonate cage in a room with controlled temperature $\left(20-25^{\circ} \mathrm{C}\right)$ and humidity (50-55\%). The light:dark cycle was $12 \mathrm{~h}: 12 \mathrm{~h}$, and standard rodent chow (Samyang Feed Co., Seoul, South Korea) and water were supplied ad libitum. All animals were treated according to international regulations for the usage and welfare of laboratory animals, and approved was obtained from the Institutional Animal Care and Use Committee of Daegu Haany University (Gyeongsan, South Korea) prior to animal experimentation. The rats were subdivided into six groups, comprising two control groups (intact and EPD control) and four treatment groups (indomethacin $5 \mathrm{mg} / \mathrm{kg}$, and PR extracts 50,100 and $200 \mathrm{mg} / \mathrm{kg}$ ).

Preparations and administration of test materials. Aqueous PR extracts (yield, 12.00\%) were prepared by routine methods using a rotary vacuum evaporator (Eyela; Tokyo Rikakikai Co., Ltd., Tokyo, Japan) and programmable freeze dryer (Operon Co., Ltd., Kimpo, South Korea) from dried stem parts of Persicaria tinctoria H. Gross (Omniherb, Yeongcheon, South Korea). The voucher specimens documenting this purchase were deposited in the herbarium of the Medical Research Center for Globalization of Herbal Formulation, Daegu Haany University. Aqueous PR was boiled at $80^{\circ} \mathrm{C}$ for $3 \mathrm{~h}$ and then, evaporated and lyophilized. Indomethacin (Sigma-Aldrich, St. Louis, MO, USA) was used as a reference.

One day after ligation placement, 50,100 or $200 \mathrm{mg} / \mathrm{kg}$ PR extracts or $5 \mathrm{mg} / \mathrm{kg}$ indomethacin was orally administered, in a volume of $5 \mathrm{ml} / \mathrm{kg}$ dissolved in distilled water (DW), once a day for 10 days, respectively. In the intact and EPD controls, same volume of DW was orally administered.

Measurement of indigo and indirubin contents in PR extracts. Standard stock solutions of indigo and indirubin (Sigma-Aldrich) were prepared by dissolving at a concentration of $1 \mu \mathrm{g} / \mathrm{ml}$ in $1 \mathrm{ml}$ dimethyl sulfoxide (DMSO; Sigma-Aldrich). For preparation of samples, the appropriate amounts of PR extracts were weighed, and dissolved in 1:1 DMSO and acetonitrile mixtures. Prior to analysis by high-performance liquid chromatography (HPLC), the samples were filtered. A Waters Alliance HPLC system (Waters Corporation, Milford,
MA, USA), equipped with a Waters 2489 UV/Visible detector was used for analysis. The Empower Data System was used for recording the output signal of the detector. A Waters YMC-Pack Pro C-18 column $(1.7 \mu \mathrm{m}, 2.1 \times 100 \mathrm{~mm})$ was used for separation. The mobile phase comprised $0.1 \%$ formic acid water and $0.1 \%$ formic acid acetonitrile (Sigma-Aldrich) with the gradient elution system at a flow rate of $1.0 \mathrm{ml} / \mathrm{min}$. The injection volume was $10 \mu \mathrm{l}$. The detection UV wavelength was set at $540 \mathrm{~nm}$, and the column temperature was room temperature.

Induction of EPD. EPD was induced by placing a sterilized nylon (3-0) thread ligature around the cervix of the upper left incisor teeth of the rats, under anesthetization with a $25-\mathrm{mg} / \mathrm{kg}$ intraperitoneal injection of Zoletile 50 (Virbac Laboratories, Paris, France) (8). The ligature was knotted on the buccal side of the tooth, resulting in a subgingival position palatinally and a supragingival position buccally. In intact vehicle control rats, the cervix of the upper left incisor tooth was identified only, instead of ligation placement.

Measurements of body weights. Changes of body weight were measured, once a day from 1 day prior to ligature placement and throughout the experimental period. To reduce individual differences, the body weight gains after 10 days of administrations were also calculated by subtracting the body weight at the start of administration from the body weights at sacrifice.

Measurements of alveolar bone loss. The rats were sacrificed via an overdose of zoletile anesthesia $(50 \mathrm{mg} / \mathrm{kg}$ ) 10-days after the first administration, and maxillary bone containing the ligature placement site were excised. The horizontal alveolar bone loss, the distance between the cusp tip and the alveolar bone, was measured using a modification of the methods of Crawford et al (21) as described by Samejima et al (3). Measurements were made along the axis of root of the upper left incisor teeth, in units of $\mathrm{mm} / \mathrm{rat}(2)$.

Microbiological analysis. The buccal gingival tissues surrounding the upper left incisor teeth were removed, and placed in $0.3 \mathrm{ml}$ brain heart infusion broth (BD Biosciences, Cockeysville, MD, USA). Immediately afterwards, the collected fragment was homogenized, plated in dilutions of 1:100 and 1:1,000 into blood agar (brain heart infusion agar supplemented with 5\% defibrinated sheep blood and henin/menadione $10 \mu \mathrm{g} / \mathrm{ml}$; BD Biosciences), and incubated at $37^{\circ} \mathrm{C}, 48 \mathrm{~h}$ under $5 \% \mathrm{CO}_{2}$ aerobic conditions. After incubation, formed colony numbers were counted in units of $\times 10^{5}$ $\mathrm{CFU} / \mathrm{g}$ tissue.

Measurement of myeloperoxidase (MPO) activity. The buccal gingival tissues surrounding the left incisor teeth were removed. The material was suspended in $0.5 \%$ hexadecyltrimethyl-ammonium bromide (Gibco; Thermo Fisher Scientific, Inc., Waltham, MA, USA) in $50 \mathrm{mM}$ potassium phosphate buffer, $\mathrm{pH}$ 6.0, to solubilize MPO. After homogenization in an ice bath for $15 \mathrm{sec}$, the samples were freeze-thawed twice. Additional buffer was added to the test tube to reach $400 \mu \mathrm{l}$ buffer per $15 \mathrm{mg}$ tissue for $12 \mathrm{~min}$. Following centrifugation at $1,000 \mathrm{x}$ g for $12 \mathrm{~min}, 0.1 \mathrm{ml}$ supernatant was added to 
$2 \mathrm{ml}$ phosphate buffer, containing $0.167 \mathrm{mg} / \mathrm{ml} o$-dianisidine dihydrochloride (Sigma-Aldrich), DW and $0.0005 \%$ hydrogen peroxide to give a final volume of $2.1 \mathrm{ml}$ per tube. The absorbance of the supernatant was measured using a spectrophotometer (Mecasys Co., Ltd., Daejeon, South Korea) at $460 \mathrm{~nm}$.

Detection of interleukin (IL)-1 $\beta$ and tumor necrosis factor (TNF)- $\alpha$ in rat maxillary gingival tissue. The buccal gingival tissue collected was homogenized and processed as described by Safieh-Garabedian et al (22) and Botelho et al (2). TNF- $\alpha$ and IL-1 $\beta$ concentrations were determined by enzyme linked immunosorbent assay kits (ab46070 and ab100768 respectively; Abcam, Cambridge, UK) according to the manufacturer's protocol. Enzymatic coloration reaction was stopped with $\mathrm{H}_{2} \mathrm{SO}_{4}$ and the absorbance was measured using a microplate reader (Tecan, Männedorf, Switzerland) at $490 \mathrm{~nm}$.

Malondialdehyde (MDA) measurement. Buccal gingival tissues were placed into a homogenization buffer comprising $50 \mathrm{mM}$ Tris- $\mathrm{HCl}, 0.1 \mathrm{mM}$ ethylene glycol-bis(2-aminoethyle ther)-N,N,N',N'-tetraacetic acid (EGTA) and $1 \mathrm{mM}$ phenylmethylsulfonyl fluoride ( $\mathrm{pH}$ 7.4) and then homogenized. An aliquot of the homogenate was added to a reaction mixture containing $8.1 \%$ (w/v) sodium dodecyl sulfate (Sigma-Aldrich), $20 \%(\mathrm{v} / \mathrm{v})$ acetic acid (pH 3.5), $0.8 \%$ (w/v) thiobarbituric acid (Sigma-Aldrich) and DW. Samples were heated for $1 \mathrm{~h}$ at $95^{\circ} \mathrm{C}$, then centrifuged at $3,000 \mathrm{x}$ for $10 \mathrm{~min}$, and finally the absorption was measured at $650 \mathrm{~nm}$.

Inducible nitric oxide synthase (iNOS) activity measurement. Buccal gingival tissue homogenate was incubated in the presence of L- $\left[{ }^{3} \mathrm{H}\right]$-arginine (10 mM, $5 \mathrm{kBq} /$ tube), NADPH (1 mM), calmodulin $(30 \mathrm{nM})$, tetrahydrobiopterin $(5 \mathrm{mM})$ and calcium $\left(2 \mathrm{mM}\right.$ ) for $30 \mathrm{~min}$ at $22^{\circ} \mathrm{C}$. Reactions were stopped by dilution with $0.5 \mathrm{ml}$ ice-cold HEPES buffer ( $\mathrm{pH}$ 5.5) containing EGTA $(2 \mathrm{mM})$ and EDTA $(2 \mathrm{mM})$. Experiments performed in the absence of NADPH determined the extent of L- $\left[{ }^{3} \mathrm{H}\right]$-citrulline formation independent of a specific NOS activity. Experiments in the presence of $\mathrm{NADH}$, without calcium, and in the presence of EGTA $(5 \mathrm{mM})$ determined the calcium-independent NOS activity. Reaction mixtures were applied to Dowex 50W (Na/form) columns and the eluted L- $\left[{ }^{3} \mathrm{H}\right]$-citrulline activity was measured using a liquid scintillation counter (Wallac; PerkinElmer, Annapolis, MD, USA).

Histopathology. Tissue from the maxillary area was fixed in $10 \%$ neutral buffered formalin., and then decalcified using decalcifying solution (24.4\% formic acid and $0.5 \mathrm{~N}$ sodium hydroxide) for 5 days. After that, the tissue was longitudinally trimmed and embedded in paraffin, sectioned (3-4 $\mu \mathrm{m})$ and stained with hematoxylin and eosin (H\&E) according to established methods (7). The areas between the left and right incisor teeth were analyzed under light microscopy using on a 0-3 score grade, considering the inflammatory cell influx, and alveolar bone and cementum integrity, as described previously (4). In addition, the numbers of infiltrated inflammatory cells (numbers $/ \mathrm{mm}^{2}$ of gingival tissues) and collagen-occupied regions ( $\% / \mathrm{mm}^{2}$ of gingival tissues) on the gingival areas between the first and second molars were measured using histomorphometrical analyses of prepared longitudinally trimmed samples using a computer-assisted image analysis program, iSolution FL version 9.1 (IMT $i$-solution Inc., Vancouver, Canada). In addition, alveolar bone volumes $\left(\% / \mathrm{mm}^{2}\right.$ alveolar bone areas), osteoclast cell numbers (numbers $/ \mathrm{mm}^{2}$ of alveolar bone surface) and their occupied percentages $\left(\% / \mathrm{mm}^{2}\right.$ of alveolar bone surface) were also measured on the alveolar bone regions between the right and left incisor. The histopathologist was blinded to the group distribution when this analysis was conducted.

Statistical analyses. Multiple comparison tests for different dose groups were conducted. If the Levene test indicated no significant deviations from variance homogeneity, the obtained data were analyzed by one-way analysis of variance testing followed by least-significant differences multi-comparison tests. In cases where significant deviations from variance homogeneity was observed in the Levene test, a Kruskal-Wallis $\mathrm{H}$ test was conducted. When a significant difference was observed in the Kruskal-Wallis H test, the Mann-Whitney $\mathrm{U}$ test was conducted to determine the specific pairs of group that were significantly different. Statistical analyses were conducted using SPSS for Windows (14.0 Korean edition; IBM SPSS, Inc., Armonk, NY, USA), and $\mathrm{P}<0.05$ was considered to indicate a statistically significant difference.

\section{Results}

Indigo and indirubin contents in PR extracts. Contents of indigo and indirubin were calculated from the calibration curves of the standards. Validation of the method verified its reliability and stability. Use of the method indicated that the lyophilized aqueous extracts of PR contain $0.043 \%$ indigo and $0.009 \%$ indirubin (Fig. 1).

Body weight changes and gains. Rats treated with the three different dosages of PR extracts showed significantly increased body weights as compared with the EPD control from 1 day after initial administration, and the body weight gains during the 10-day administration period were significantly increased in these PR extract-treated rats, respectively. By contrast, the rats treated with indomethacin exhibited significantly lower body weights compared with the EPD control from 9 days after the initiation of treatment; consequently, the body weight gain during the 10-days administration period was also significantly decreased in the indomethacin group compared with the EPD control (Fig. 2).

Changes in alveolar bone loss measurements. Significant reductions in the extent of alveolar bone loss were detected in the rats treated with indomethacin, or 50,100 or $200 \mathrm{mg} / \mathrm{kg}$ PR extracts as compared with the EPD control (Fig. 3).

Changes in gingival viable bacteria counts. Significant and dose-dependent reductions in the numbers of viable bacteria (colony numbers) were detected in the three PR extract-treated groups compared with the EPD control. No significant changes in viable bacteria numbers were demonstrated in the indomethacin-treated rats as compared with the EPD control in this experiment (Fig. 4A). 
A

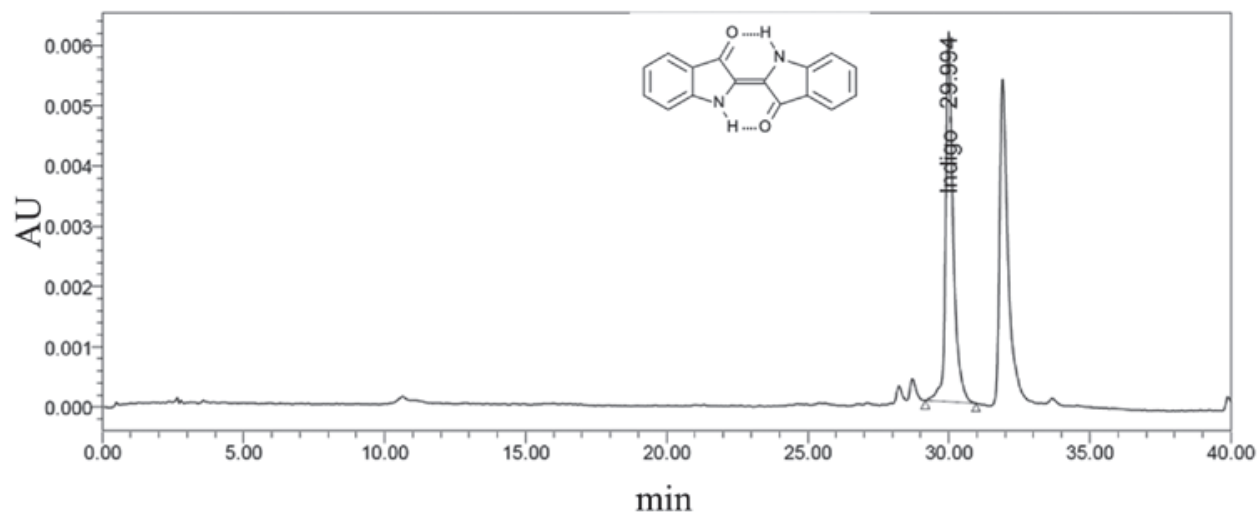

B

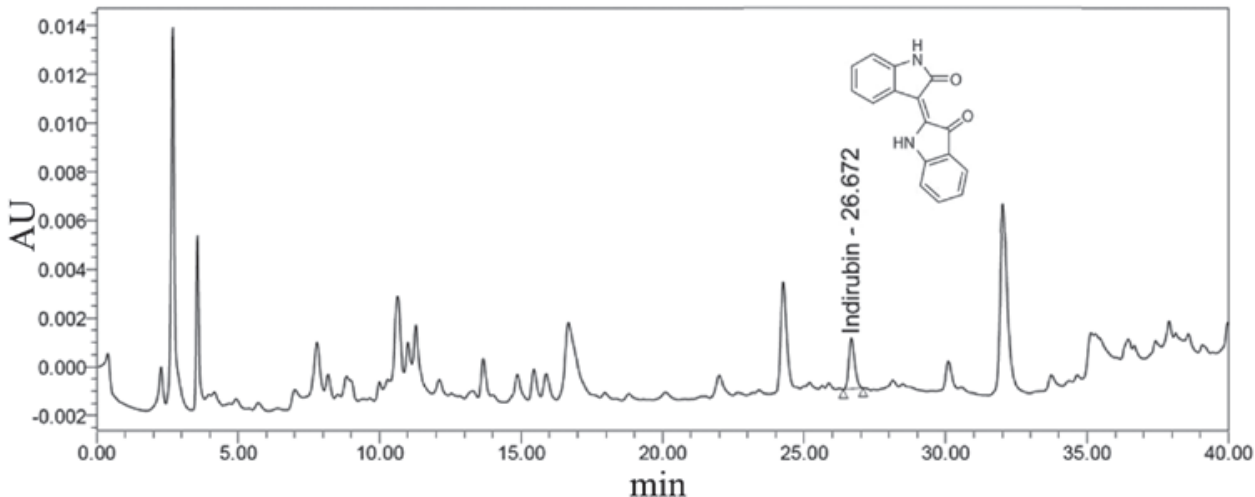

Figure 1. HPLC chromatograms of (A) indigo and (B) indirubin in PR extract. Determination of indigo and indirubin in PR extracts was established using HPLC, and revealed that the lyophilized aqueous extracts of PR contained $0.043 \%$ indigo and $0.009 \%$ indirubin. HPLC, high-performance liquid chromatography; PR, Persicariae Rhizoma; AU, absorption units.

A

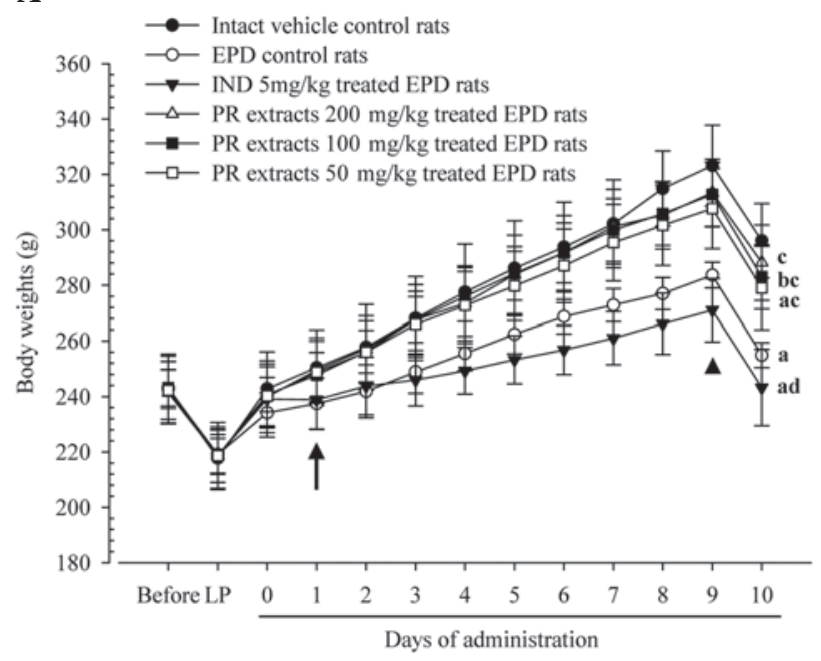

B

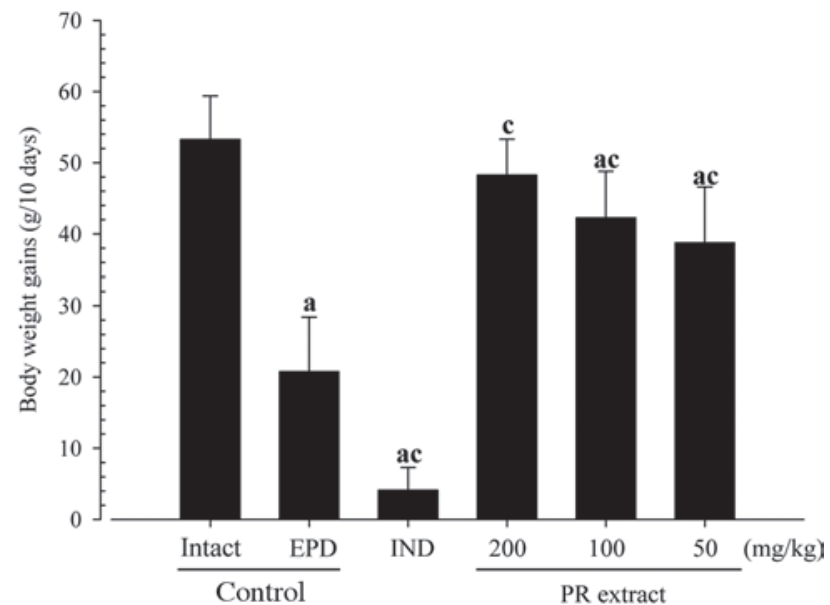

Figure 2. (A) Changes of body weights and (B) body weight gains after 10 days of continued oral administration of IND or PR extract in a rat model of EPD. Rats treated with each of the three different dosages of PR extract showed significantly increased body weights as compared with the EPD control from 1 day after initial administration (arrow), and body weight gains during the 10-day administration period were also significantly increased in these PR extract-treated rats. By contrast, the body weights of IND-treated rats were significantly lower than those of the EPD control (arrowhead) from 9 days after the initiation of treatment. Consequently, body weight gains during the 10-day administration period were also significantly decreased by IND. Values are expressed as the mean \pm standard deviation $(\mathrm{n}=8)$. Before is 1 day before ligature placement, and LP is at ligation. IND, indomethacin; PR, Persicariae Rhizoma; EPD, experimental periodontitis. ${ }^{a} \mathrm{P}<0.01$ and ${ }^{\mathrm{b}} \mathrm{P}<0.05$ vs. intact control; ${ }^{\mathrm{C}} \mathrm{P}<0.01$ and ${ }^{\mathrm{d}} \mathrm{P}<0.05$ vs. EPD control, as determined by least significant difference tests.

Changes in gingival MPO activities. Significant reductions of MPO activities in the buccal gingival tissues were detected in the four treatment groups as compared with the EPD control, respectively. Notably, the PR extracts exhibited a clear dose-dependent inhibitory effect against the EPD-related elevations of gingival MPO activities in this experiment (Fig. 4B). 

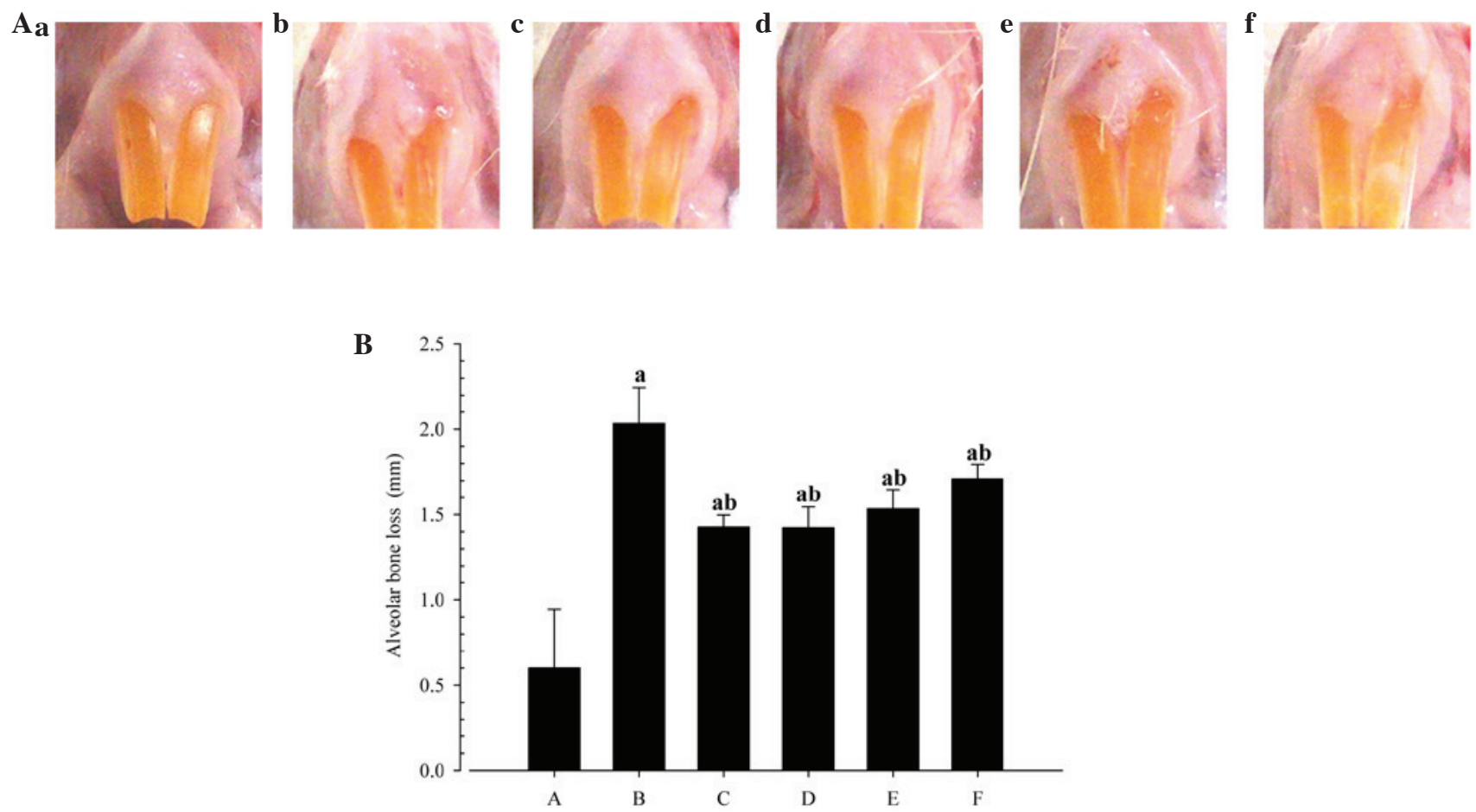

Figure 3. (A) Representative gross images of ligation-placed regions and (B) changes in alveolar bone loss measurements in a rat model of EPD. Significant reductions in the extent of alveolar bone loss were detected in IND- and PR extract (200, 100 and $50 \mathrm{mg} / \mathrm{kg})$-treated rats as compared with the EPD control. Values are expressed mean \pm standard deviation ( $\mathrm{n}=8$ ). (Aa) Intact control; (Ab) EPD control; (Ac) 5 mg/kg indomethacin-treated EPD rats; (Ad) 200 mg/kg

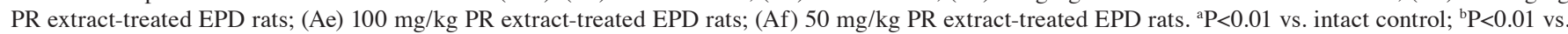
EPD control by Mann-Whitney U test. EPD, experimental periodontitis; IND, indomethacin; PR, Persicariae Rhizoma.
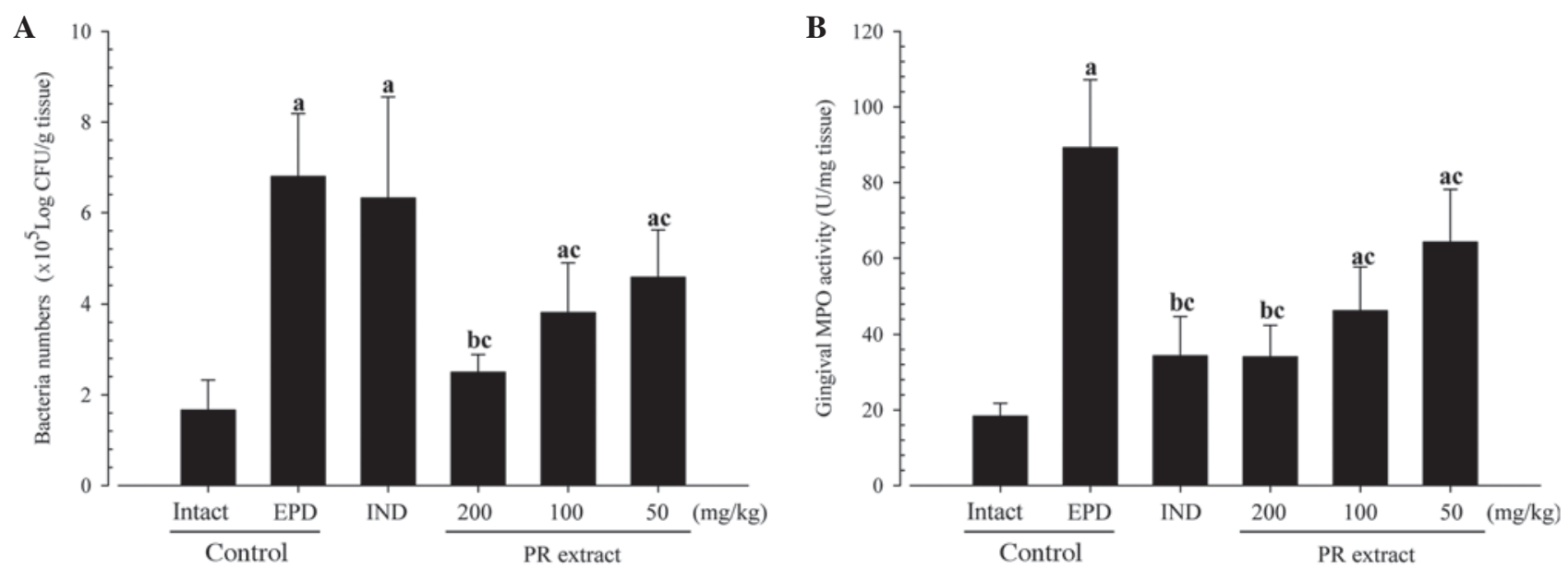

Figure 4. (A) Gingival viable bacteria counts and (B) MPO activities in a rat model of EPD. Significant and dose-dependent reductions in viable bacteria numbers and gingival MPO activities were detected in the three PR extract groups as compared with the EPD control. No significant changes in viable bacteria numbers were demonstrated in the IND-treated rats as compared with the EPD control. However, significant reductions of gingival MPO activities were detected in the indomethacin group as compared with the EPD control. Values are expressed mean \pm standard deviation $(\mathrm{n}=8)$. ${ }^{\mathrm{a}} \mathrm{P}<0.01$ and ${ }^{\mathrm{b}} \mathrm{P}<0.05 \mathrm{vs}$. intact control; ${ }^{\mathrm{P}} \mathrm{P}<0.01$ vs. EPD control by Mann-Whitney U test. MPO, myeloperoxidase; EPD, experimental periodontitis; PR, Persicariae Rhizoma; IND, indomethacin; $\mathrm{CFU}$, colony forming units.

Changes in gingival IL-1 $\beta$ and TNF- $\alpha$ levels. The elevations in the levels of gingival IL-1 $\beta$ and TNF- $\alpha$ induced by EPD were demonstrated to be significantly and dose-dependently inhibited by treatment with 50,100 and $200 \mathrm{mg} / \mathrm{kg}$ PR extracts $(\mathrm{P}<0.01)$. In addition, the rats treated with $5 \mathrm{mg} / \mathrm{kg}$ indomethacin also exhibited significantly decreased gingival IL-1 $\beta$ and TNF- $\alpha$ levels as compared with the EPD control rats $(\mathrm{P}<0.01$; Table I).
Changes in gingival MDA levels and iNOS activities. Statistically significant reductions in gingival MDA levels and iNOS activities were observed in each of the four groups of rats with EPD that were treated with test substances, including indomethacin, as compared with the EPD control. Notably, PR extracts were observed to have a clear dose-dependent inhibitory activity against the elevations of gingival MDA levels and iNOS activities that were induced by EPD (Table I). 
Table I. Gingival IL-1 $\beta$, TNF- $\alpha$ and MDA levels and iNOS activities around the ligation site in EPD model rats.

\begin{tabular}{|c|c|c|c|c|}
\hline \multirow[b]{2}{*}{ Group } & \multicolumn{2}{|c|}{ Pro-inflammatory cytokines } & \multicolumn{2}{|c|}{ Antioxidative stresses } \\
\hline & $\mathrm{IL}-1 \beta(\mathrm{pg} / \mathrm{ml})$ & TNF- $\alpha(\mathrm{pg} / \mathrm{ml})$ & MDA $(\mu \mathrm{M} / \mathrm{mg}$ tissue $)$ & iNOS (fM/mg/min) \\
\hline \multicolumn{5}{|l|}{ Controls } \\
\hline Intact & $22.05 \pm 7.88$ & $229.25 \pm 36.63$ & $1.69 \pm 0.43$ & $25.35 \pm 10.97$ \\
\hline EPD & $63.40 \pm 9.81^{\mathrm{a}}$ & $824.13 \pm 194.75^{\mathrm{a}}$ & $8.96 \pm 1.63^{\mathrm{a}}$ & $207.39 \pm 56.02^{\mathrm{a}}$ \\
\hline Indomethacin $5 \mathrm{mg} / \mathrm{kg}$ & $37.88 \pm 4.64^{\mathrm{a}, \mathrm{b}}$ & $458.25 \pm 142.40^{\mathrm{a}, \mathrm{b}}$ & $5.99 \pm 0.97^{\mathrm{a}, \mathrm{b}}$ & $133.09 \pm 26.97^{\mathrm{a}, \mathrm{b}}$ \\
\hline \multicolumn{5}{|l|}{ PR extracts } \\
\hline $50 \mathrm{mg} / \mathrm{kg}$ & $50.61 \pm 7.67^{\mathrm{a}, \mathrm{b}}$ & $600.75 \pm 78.60^{\mathrm{a}, \mathrm{b}}$ & $6.87 \pm 1.10^{\mathrm{a}, \mathrm{c}}$ & $149.79 \pm 9.90^{\mathrm{a}, \mathrm{b}}$ \\
\hline $100 \mathrm{mg} / \mathrm{kg}$ & $45.93 \pm 9.40^{\mathrm{a}, \mathrm{b}}$ & $539.63 \pm 79.30^{\mathrm{a}, \mathrm{b}}$ & $6.34 \pm 0.80^{\mathrm{a}, \mathrm{b}}$ & $142.99 \pm 17.65^{\mathrm{a}, \mathrm{b}}$ \\
\hline $200 \mathrm{mg} / \mathrm{kg}$ & $49.23 \pm 6.33^{\mathrm{a}, \mathrm{b}}$ & $456.00 \pm 126.53^{\mathrm{a}, \mathrm{b}}$ & $5.91 \pm 1.27^{\mathrm{a}, \mathrm{b}}$ & $135.00 \pm 21.85^{\mathrm{a}, \mathrm{b}}$ \\
\hline
\end{tabular}

Values are expressed as mean \pm standard deviation $(\mathrm{n}=8)$. ${ }^{\mathrm{a}} \mathrm{P}<0.01 \mathrm{vs}$. intact control, ${ }^{\mathrm{b}} \mathrm{P}<0.01 \mathrm{vs}$. EPD control and ${ }^{\mathrm{c}} \mathrm{P}<0.05 \mathrm{vs}$. EPD control, all by least significant difference tests. IL, interleukin; TNF, tumor necrosis factor; MDA, malondialdehyde; iNOS, inducible nitric oxide synthase; EPD, experimental periodontitis; PR, Persicariae Rhizoma.

Table II. Histomorphometrical analysis of maxillary regions around the ligation site - gingival and alveolar bone areas in EPD model rats.

\begin{tabular}{|c|c|c|c|c|c|c|}
\hline \multirow[b]{2}{*}{ Group } & \multirow[b]{2}{*}{ Histological score } & \multicolumn{2}{|c|}{ Gingival areas } & \multicolumn{3}{|c|}{ Alveolar bone areas } \\
\hline & & $\begin{array}{c}\text { Inflammatory } \\
\text { cells }\left(\text { cells } / \mathrm{mm}^{2}\right)\end{array}$ & $\begin{array}{l}\text { Collagen } \\
\left(\% / \mathrm{mm}^{2}\right)\end{array}$ & $\begin{array}{c}\text { Alveolar bone } \\
\text { volume }(\%)\end{array}$ & $\begin{array}{l}\text { Osteoclast cells } \\
\quad(\text { cells } / \mathrm{mm})\end{array}$ & $\begin{array}{c}\mathrm{OS} / \mathrm{BS} \\
(\%)\end{array}$ \\
\hline \multicolumn{7}{|l|}{ Controls } \\
\hline Intact & $0.75 \pm 0.46$ & $9.88 \pm 3.80$ & $72.32 \pm 10.79$ & $75.92 \pm 7.03$ & $6.50 \pm 1.93$ & $1.56 \pm 0.93$ \\
\hline EPD & $2.88 \pm 0.35^{\mathrm{a}}$ & $1,010.38 \pm 171.56^{\mathrm{a}}$ & $28.60 \pm 11.30^{\mathrm{a}}$ & $37.95 \pm 5.28^{\mathrm{a}}$ & $43.63 \pm 12.39^{\mathrm{a}}$ & $40.60 \pm 10.58^{\mathrm{a}}$ \\
\hline $\begin{array}{l}\text { Indomethacin } \\
5 \mathrm{mg} / \mathrm{kg}\end{array}$ & $1.75 \pm 0.46^{\mathrm{a}, \mathrm{b}}$ & $263.50 \pm 83.94^{\mathrm{a}, \mathrm{b}}$ & $51.27 \pm 11.47^{\mathrm{a}, \mathrm{b}}$ & $52.13 \pm 4.45^{\mathrm{a}, \mathrm{b}}$ & $24.88 \pm 8.97^{\mathrm{a} . \mathrm{b}}$ & $17.99 \pm 6.59^{\mathrm{a} . \mathrm{b}}$ \\
\hline \multicolumn{7}{|l|}{ PR extracts } \\
\hline $50 \mathrm{mg} / \mathrm{kg}$ & $2.13 \pm 0.64^{\mathrm{a}, \mathrm{b}}$ & $780.13 \pm 106.57^{\mathrm{a}, \mathrm{c}}$ & $41.80 \pm 7.11^{\mathrm{a}, \mathrm{c}}$ & $47.83 \pm 7.53^{\mathrm{a}, \mathrm{c}}$ & $27.38 \pm 4.66^{\mathrm{a}, \mathrm{c}}$ & $23.70 \pm 4.33^{\mathrm{a}, \mathrm{b}}$ \\
\hline $100 \mathrm{mg} / \mathrm{kg}$ & $2.00 \pm 0.53^{\mathrm{a}, \mathrm{b}}$ & $313.13 \pm 100.50^{\mathrm{a}, \mathrm{b}}$ & $45.36 \pm 10.38^{\mathrm{a}, \mathrm{b}}$ & $50.51 \pm 7.22^{\mathrm{a}, \mathrm{b}}$ & $25.75 \pm 7.17^{\mathrm{a}, \mathrm{b}}$ & $19.97 \pm 3.58^{\mathrm{a}, \mathrm{b}}$ \\
\hline $200 \mathrm{mg} / \mathrm{kg}$ & $1.88 \pm 0.35^{\mathrm{a}, \mathrm{b}}$ & $259.50 \pm 41.29^{\mathrm{a}, \mathrm{b}}$ & $51.14 \pm 9.13^{\mathrm{a}, \mathrm{b}}$ & $56.88 \pm 12.04^{\mathrm{a}, \mathrm{b}}$ & $22.25 \pm 3.92^{\mathrm{a}, \mathrm{b}}$ & $14.26 \pm 4.73^{\mathrm{a}, \mathrm{b}}$ \\
\hline
\end{tabular}

Values are expressed as mean \pm standard deviation $(\mathrm{n}=8) .{ }^{\mathrm{a}} \mathrm{P}<0.01 \mathrm{vs}$. intact control, ${ }^{\mathrm{b}} \mathrm{P}<0.01$ and ${ }^{\mathrm{c}} \mathrm{P}<0.05$ vs. EPD control, all by least significant difference tests. EPD, experimental periodontitis; PR, Persicariae Rhizoma; OS, osteoid surface; BS, bone surface.

Histopathological changes of maxillary regions. Marked increases in inflammatory cell infiltrations, predominantly polymorphneutrophils, were detected in the gingival tissues between upper left and right incisor teeth in the EPD control rats with severe edematous changes (loosening of collagen fibers and loss of compactness). In addition, activation of osteoclast cells, increases in the number and the percentages of osteoclast cells occupied regions on the alveolar bone surface (OS/BS), were also observed in the alveolar bone areas of the EPD control rats with marked decreases of osteoid alveolar bones; they were re-confirmed by histomorphometrical analysis. Significant $(\mathrm{P}<0.01)$ increases in the histological scores, infiltrated inflammatory cell numbers in gingival tissues, and decreased collagen fiber occupied regions in gingival tissues were demonstrated in the EPD control rats, along with significant $(\mathrm{P}<0.01)$ decreases in alveolar bone volumes, increased osteoclast cell numbers and OS/BS, as compared with those of intact control rats, respectively. However, these histopathological periodontitis and associated alveolar bone losses were significantly $(\mathrm{P}<0.05)$ and dose-dependently reduced by treatment of all three different dosages of PR extracts, as compared with EPD control rats, respectively. In addition, indomethacin was also observed to significantly ameliorate the EPD-induced periodontitis and related alveolar bone losses, as revealed by histopathological inspections in this experiment (Table II and Fig. 5).

\section{Discussion}

The present study demonstrated that PR has effective inhibitory effects against ligation-induced EPD and associated alveolar bone loss, which are mediated by antibacterial, antioxidative and anti-inflammatory activities. 


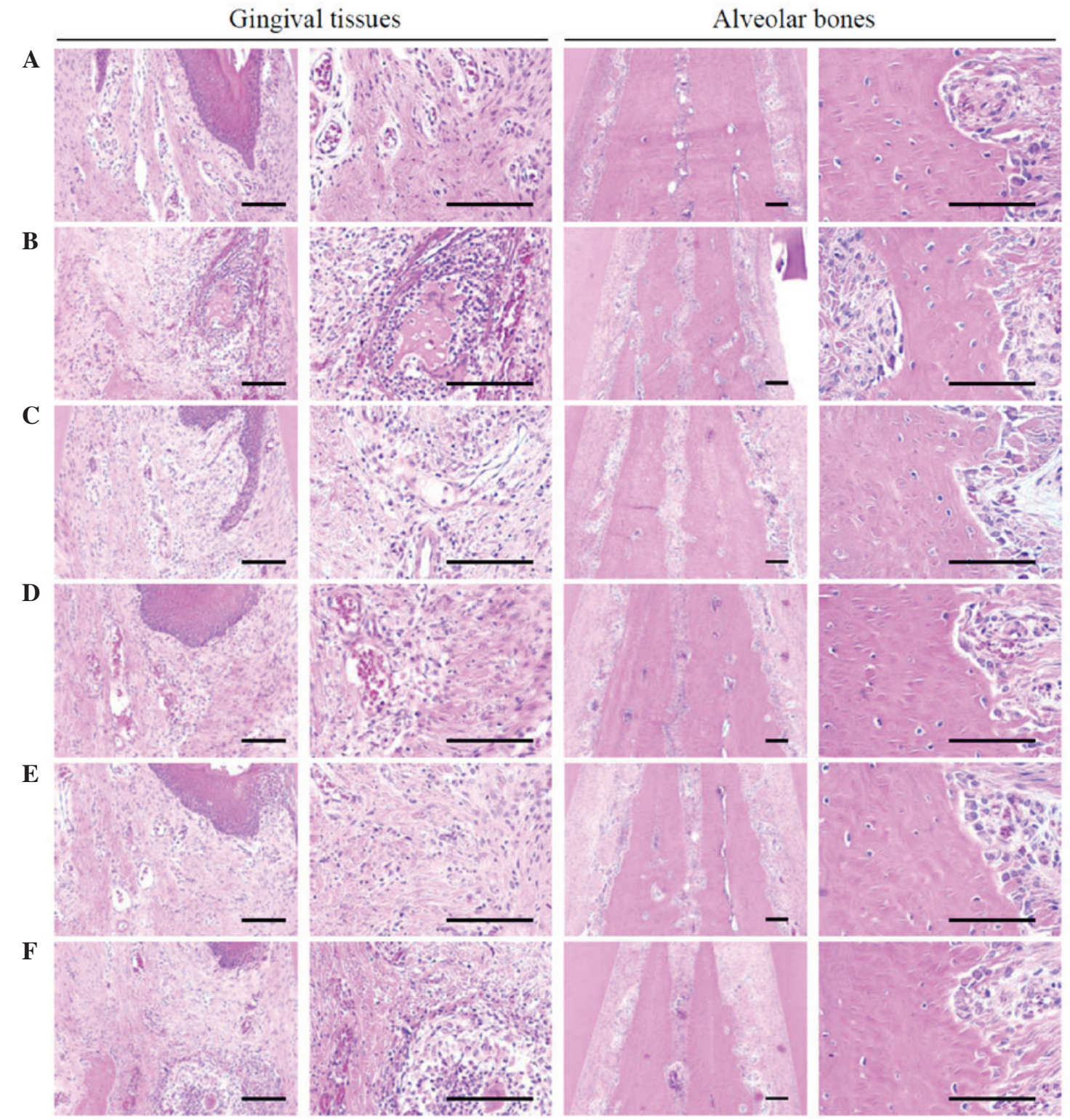

Figure 5. Representative histological images of gingival tissues and alveolar bones between upper incisor teeth, taken from around the upper left incisor teeth of intact or rats with EPD. (A) Intact control, (B) EPD control, (C) $5 \mathrm{mg} / \mathrm{kg}$ indomethacin-treated EPD rats, (D) $200 \mathrm{mg} / \mathrm{kg}$ PR extract-treated EPD rats, (E) $100 \mathrm{mg} / \mathrm{kg}$ PR extract-treated EPD rats and (F) $50 \mathrm{mg} / \mathrm{kg}$ PR extract-treated EPD rats. Marked increases of inflammatory cell infiltrations were detected in the gingival tissues between the upper left and right incisor teeth in EPD control rats with severe edematous changes, with the loosening of collagen fibers and loss of their compactness. In addition, activation of osteoclast cells, increases in the number of osteoclast cells and the percentage of the region they occupy on the alveolar bone surface were also observed in the alveolar bone areas of the EPD control with marked reductions of osteoid alveolar bone. However, these histopathological features of periodontitis and related alveolar bone loss were obviously and dose-dependently reduced by treatment with all three different dosages of PR extract as compared with the EPD control. In addition, indomethacin also markedly ameliorated the EPD-induced periodontitis and related alveolar bone loss as revealed by these histopathological inspections. All hematoxylin and eosin stained; scale bars, $120 \mu \mathrm{m}$.

Periodontitis and the alveolar bone loss associated with it in EPD directly induce mal-mastication, which results in marked loss of body weight (2). Therefore, the inhibition of these EPD-related body weight reductions can be considered to be indirect evidence that a treatment ameliorates periodontitis and alveolar bone loss. In the present study, marked increases in body weight and gains in body weight over the 10-day treatment period were detected in the rats treated with PR extracts, as compared with the EPD control, and these increases were dose-dependent.

Measuring alveolar bone loss on the basis of the exposure of tooth roots from alveolar sockets is a generally used macroscopical evaluation method for alveolar bone loss $(2,23)$.
Significant reductions in the alveolar bone loss measurements by indomethacin, and 50, 100 or $200 \mathrm{mg} / \mathrm{kg}$ PR extracts provides direct evidences that these treatments ameliorated EPD-related alveolar bone loss.

Bacteria are considered to be the primary etiologic agents of periodontal disease (24). Bacterial plaque is considered to be involved in the pathogenesis of periodontitis, and may initiate a local inflammatory reaction (2), leading to edema, leukocyte infiltration and the release of inflammatory mediators, which may cause the formation of periodontal pockets, detachment of connective tissue and resorption of alveolar bone, ultimately leading to tooth loss $(3,4)$. Previous studies have indicated that periodontal microbial flora change during periodontal disease 
in rats following the cervical ligation of teeth, with anaerobic gram-negative bacilli becoming predominant $(2,4)$. The present study demonstrated that marked increases in viable total bacteria numbers occurred in gingival tissues around ligature-bound incisor teeth. However, significant reductions in viable bacteria numbers were dose-dependently detected in PR extract-treated rats, but not in those treated with indomethacin, suggesting the existence of different mechanisms of action between PR extracts and indomethacin. It is suggested that indomethacin is a representative anti-inflammatory agent whose actions are mediated by cyclooxygenase inhibition, whereas PR extracts contain antibacterial dyes, namely indigo and indirubin (17).

The importance of acute inflammatory cells, particularly polymorphonuclear neutrophil (PMN) infiltrations, on gingival tissue in the evolution of periodontal disease has been demonstrated previously (4). Although, inflammatory cells play key roles in eliminating the causes of inflammations (25), activated PMNs also generate oxygen metabolites (26). MPO is an activating cytotoxic enzyme released from PMNs (27), and its levels are markedly increased in periodontal diseases $(2,28)$. In the present study, significant increase in gingival MPO levels were detected in the EPD control; however, PR extracts significantly inhibited these increases, suggesting that PR extracts suppressed the cytotoxic effects of PMNs.

Pro-inflammatory cytokines, particularly TNF- $\alpha$ and IL-1 $\beta$, have been shown to play a significant role in periodontal disease (29). The cytokine TNF- $\alpha$, which is produced by a variety of cell types, including splenocytes, has been found to be associated with critical events leading to T-lineage commitment and differentiation (30). Periodontitis may be potentiated by the TNF-stimulated release of eicosanoids and other cytokines, such as TNF- $\alpha$ and IL-1. IL-1 activates neutrophils and macrophages, and thereby induces the production and release of reaction oxygen species and nitric oxide, which has been implicated to be a cause of local tissue damage (31). In the present study, significant decreases of gingival TNF- $\alpha$ and IL-1 $\beta$ levels were detected in all test substance-treated rats as compared with the EPD control, providing direct evidence that their anti-inflammatory effects are sufficient to ameliorate the periodontitis induced by ligation placement.

MDA is an index of lipid peroxidation (32) and its levels are increased in periodontal diseases (33). iNOS a distinct isoform of NOS that can be induced by proinflammatory agents such as endotoxin, IL-1 $\beta$, TNF- $\alpha$ and interferon- $\gamma$ in a variety of cells. Increased production of NO following the induction of iNOS has been implicated in the pathogenesis of shock and inflammation (34). In periodontal diseases, activation of iNOS and associated increases in NO production have been found to occur, and accordingly, this induces damage of the surrounding tissues, particularly the alveolar bones $(33,35)$. In the present study, the increments of MDA levels and iNOS activities were significantly decreased by treatment with both PR extracts and indomethacin, providing direct evidence that they exhibit antioxidant effects on the periodontal tissue damage caused by increases of NO production through the elevation of iNOS activities induced by ligature placements.

Consistent with previous studies of $\operatorname{EPD}(7,8)$, marked inflammatory cell infiltrations and edematous changes were detected in the gingival tissues between the first and second molars, where the ligature was placed. In addition, absorption of the alveolar bones due to osteoclast cell activation was detected during the histopathological observations in this study. Increases in histological scores based on inflammatory cell infiltration and alveolar bone damage $(2,23)$, infiltration of inflammatory cells (including neutrophils), reductions of collagen-occupied regions associated with edematous changes, reductions of bone volumes, increases of osteoclast cell numbers and osteoid surface/bone surface ratios were detected by the histomorphometrical analysis in the present study, and these findings are quite similar to those of previous studies $(7,8)$. However, these histopathological changes associated with periodontitis and alveolar bone loss were significantly and dose-dependently inhibited by treatment with each of the three different dosages of PR extracts, and by indomethacin.

In summary, the results indicate that aqueous PR extracts contain blue indigo (0.043\%) and purple indirubin (0.009\%), and effectively ameliorates ligature placement-induced periodontitis and associated alveolar bone loss by a combination of antibacterial, antioxidative and anti-inflammatory activities. PR exhibits promise as a potent protective agent for various periodontal diseases in the future.

\section{Acknowledgements}

This study was supported by the Basic Science Research Program through the National Research Foundation of Korea (NRF) funded by the Ministry of Education, Science and Technology (grant no. NRF-2012R1A1A2043886).

\section{References}

1. Chambrone LA and Chambrone L: Tooth loss in well-maintained patients with chronic periodontitis during long-term supportive therapy in Brazil. J Clin Periodontol 33: 759-764, 2006.

2. Botelho MA, Rao VS, Carvalho CB, Bezerra-Filho JG, Fonseca SG, Vale ML, Montenegro D, Cunha F, Ribeiro RA and Brito GA: Lippia sidoides and Myracrodruon urundeuva gel prevents alveolar bone resorption in experimental periodontitis in rats. J Ethnopharmacol 113: 471-478, 2007.

3. Samejima Y, Ebisu S and Okada H: Effect of infection with Eikenella corrodens on the progression of ligature-induced periodontitis in rats. J Periodontal Res 25: 308-315, 1990.

4. Menezes AM, Rocha FA, Chaves HV, Carvalho CB, Ribeiro RA and Brito GA: Effect of sodium alendronate on alveolar bone resorption in experimental periodontitis in rats. J Periodontol 76: 1901-1909, 2005.

5. Listgarten MA: Nature of periodontal diseases: Pathogenic mechanisms. J Periodontal Res 22: 172-178, 1987.

6. Fentoğlu Ö, Kırzıoğlu FY, Bulut MT, Kumbul Doğuç D, Kulaç E, Önder C and Günhan M: Evaluation of lipid peroxidation and oxidative DNA damage in patients with periodontitis and hyperlipidemia. J Periodontol 86: 682-688, 2015.

7. Kim YS, Kang SJ, Kim JW, Cho HR, Moon SB, Kim KY, Lee HS, Han CH, Ku SK and Lee YJ: Effects of Polycan, a $\beta$-glucan, on experimental periodontitis and alveolar bone loss in Sprague-Dawley rats. J Periodontal Res 47: 800-810, 2012.

8. Ku SK, Cho HR, Sung YS, Kang SJ and Lee YJ: Effects of calcium gluconate on experimental periodontitis and alveolar bone loss in rats. Basic Clin Pharmacol Toxicol 108: 241-250, 2011.

9. Toker H, Ozdemir H, Eren K, Ozer H and Sahin G: $\mathrm{N}$-acetylcysteine, a thiol antioxidant, decreases alveolar bone loss in experimental periodontitis in rats. J Periodontol 80: 672-678, 2009.

10. Park JH, Seo BI, Cho SY, Park KR, Choi SH, Han CK, Song CH, Park SJ and Ku SK: Single oral dose toxicity study of prebrewed armeniacae semen in rats. Toxicol Res 29: 91-98, 2013. 
11. Noh JR, Kim YH, Gang GT, Hwang JH, Kim SK, Ryu SY, Kim YS, Lee HS and Lee CH: Hepatoprotective effect of Platycodon grandiflorum against chronic ethanol-induced oxidative stress in C57BL/6 mice. Ann Nutr Metab 58: 224-231, 2011.

12. Woo YM, Kim AJ, Kim JY and Lee CH: Tyrosinase inhibitory compounds isolated from Persicaria tinctoria flower. J Appl Biol Chem 54: 47-50, 2011.

13. Kim SJ, Ko JH, Park SH, Kim MS and Kim KS: Preparation method of indigo standard solution and variation of indigo contents in blue dye extract from breeding lines of Persicaria tinctoria H. Gross. Korean J Medicinal Crop Sci 21: 213-219, 2013 (In Korean).

14. Xiao Z, Hao Y, Liu B and Qian L: Indirubin and meisoindigo in the treatment of chronic myelogenous leukemia in China. Leuk Lymphoma 43: 1763-1768, 2002.

15. Mok CK, Kang SS, Chan RW, Yue PY, Mak NK, Poon LL, Wong RN, Peiris JS and Chan MC: Anti-inflammatory and antiviral effects of indirubin derivatives in influenza A (H5N1) virus infected primary human peripheral blood-derived macrophages and alveolar epithelial cells. Antiviral Res 106: 95-104, 2014.

16. Hoessel R, Leclerc S, Endicott JA, Nobel ME, Lawrie A, Tunnah P, Leost M, Damiens E, Marie D, Marko D, et al: Indirubin, the active constituent of a Chinese antileukaemia medicine, inhibits cyclin-dependent kinases. Nat Cell Biol 1: 60-67, 1999.

17. Kataoka M, Hirata K, Kunikata T, Ushio S, Iwaki K, Ohashi K, Ikeda $\mathrm{M}$ and Kurimoto $\mathrm{M}$ : Antibacterial action of tryptanthrin and kaempferol, isolated from the indigo plant (Polygonum tinctorium Lour.), against Helicobacter pylori-infected Mongolian gerbils. J Gastroenterol 36: 5-9, 2001.

18. Jang HG, Heo BG, Park YS, Namiesnik J, Barasch D, Katrich E, Vearasilp K, Trakhtenberg S and Gorinstein S: Chemical composition, antioxidant and anticancer effects of the seeds and leaves of indigo (Polygonum tinctorium Ait.) plant. Appl Biochem Biotechnol 167: 1986-2004, 2012.

19. Lin YK, Leu YL, Huang TH, Wu YH, Chung PJ, Su Pang JH and Hwang TL: Anti-inflammatory effects of the extract of indigo naturalis in human neutrophils. J Ethnopharmacol 125: 51-58, 2009.

20. Lin YK, Chen HW, Yang SH, Leu YL, Huang YH and Yen HC: Protective effect of indigo naturalis extract against oxidative stress in cultured human keratinocytes. J Ethnopharmacol 139: 893-896, 2012

21. Crawford JM, Taubman MA and Smith DJ: The natural history of periodontal bone loss in germfree and gnotobiotic rats infected with periodontopathic microorganisms. J Periodontal Res 13: 316-325, 1978

22. Safieh-Garabedian B, Poole S, Allchorne A, Winter J and Woolf CJ: Contribution of interleukin-1 beta to the inflammation-induced increase in nerve growth factor levels and inflammatory hyperalgesia. Br J Pharmacol 115: 1265-1275, 1995.
23. Azoubel MC, Menezes AM, Bezerra D, Oria RB, Ribeiro RA and Brito GA: Comparison of etoricoxib and indomethacin for the treatment of experimental periodontitis in rats. Braz $\mathrm{J}$ Med Biol Res 40: 117-125, 2007

24. Ximénez-Fyvie LA, Haffajee AD and Socransky SS: Microbial composition of supra- and subgingival plaque in subjects with adult periodontitis. J Clin Periodontol 27: 722-732, 2000.

25. Zimmerman BJ, Grisham MB and Granger DN: Role of oxidants in ischemia/reperfusion-induced granulocyte infiltration. Am J Physiol 258: G185-G190, 1990.

26. Sullivan GW, Sarembock IJ and Linden J: The role of inflammation in vascular diseases. J Leukoc Biol 67: 591-602, 2000.

27. Iseri SO, Sener G, Yüksel M, Contuk G, Cetinel S, Gedik N and Yegen BC: Ghrelin against alendronate-induced gastric damage in rats. J Endocrinol 187: 399-406, 2005.

28. Holanda Pinto SA, Pinto LM, Cunha GM, Chaves MH, Santos FA and Rao VS: Anti-inflammatory effect of alpha, beta-Amyrin, a pentacyclic triterpene from Protium heptaphyllum in rat model of acute periodontitis. Inflammopharmacology 16 : 48-52, 2008.

29. Lima V, Vidal FD, Rocha FA, Brito GA and Ribeiro RA Effects of tumor necrosis factor-alpha inhibitors pentoxifylline and thalidomide on alveolar bone loss in short-term experimental periodontal disease in rats. J Periodontol 75: 162-168, 2004.

30. Samira S, Ferrand C, Peled A, Nagler A, Tovbin Y, Ben-Hur H, Taylor N, Globerson A and Lapidot T: Tumor necrosis factor promotes human T-cell development in nonobese diabetic/severe combined immunodeficient mice. Stem Cells 22: 1085-1100, 2004.

31. Assuma R, Oates T, Cochran D, Amar S and Graves DT: IL-1 and TNF antagonists inhibit the inflammatory response and bone loss in experimental periodontitis. J Immunol 160: 403-409, 1998

32. Cuzzocrea S, Zingarelli B, Hake P, Salzman AL and Szabó C: Antiinflammatory effects of mercaptoethylguanidine, a combined inhibitor of nitric oxide synthase and peroxynitrite scavenger, in carrageenan-induced models of inflammation. Free Radic Biol Med 24: 450-459, 1998.

33. Di Paola R, Marzocco S, Mazzon E, Dattola F, Rotondo F, Britti D, De Majo M, Genovese T and Cuzzocrea S: Effect of aminoguanidine in ligature-induced periodontitis in rats. $\mathrm{J}$ Dent Res 83: 343-348, 2004.

34. Southan GJ and Szabó C: Selective pharmacological inhibition of distinct nitric oxide synthase isoforms. Biochem Pharmacol 51: 383-394, 1996.

35. Lohinai Z, Benedek P, Fehér E, Györfi A, Rosivall L, Fazekas A, Salzman AL and Szabó C: Protective effects of mercaptoethylguanidine, a selective inhibitor of inducible nitric oxide synthase, in ligature-induced periodontitis in the rat. Br J Pharmacol 123: 353-360, 1998. 